\title{
Comparison of the
} Photoisomerization and Relaxation Processes Studied by Time Resolved Spectroscopic Methods in Two Polymethine Dyes with the Same Polymethine Chromophor

\author{
S. RENTSCH, U. W. GRUMMT and D. KHETCHINASHWILI \\ Friederich-Schiller-University, Department of Physics, Department of \\ Chemistry, DDR-6900 Jena, Max-Wien-Platz 1
}

(Received August 13, 1986; in final form August 13, 1986)

A streptocyanine dye (BMC) and an oxadicarbocyanine (DODCI) were studied in the picosecond and millisecond time region. The comparison showed that for both dyes the following parameters are nearly equal: the radiative lifetime, the difference between the absorption maxima of the stable form and the photoisomer, the activation energy and the frequency factor for the thermal backreaction and even the energy barrier in the excited state.

The dyes show strongly different kinetics in the excited state. BMC relaxes faster by about 2 orders of magnitude than DODCI and shows a much higher photoisomerization rate. In accordance with Eyring's theory the higher relaxation and isomerization rate of BMC is connected with an entropy increase in the transition state.

KEY WORDS: Pholoisomerization, ps-absorption spectroscopy, polymethine dyes.

\section{INTRODUCTION}

Photoisomers of polymethine dyes were found first by irradiation of solutions at low temperature and were detected by their absorption spectra $^{1,2}$. Time resolved flash spectroscopic studies yielded lifetimes 
of the photoisomers in the millisecond range and shorter (e.g. ${ }^{1,4}$ ). Quantum chemical calculations showed an alternate $\pi$-electron density along the polymethine chain. In the excited state the $\pi$-electron distribution alters and the bond order is less than in the ground state ${ }^{3}$. $\mathrm{X}$-ray studies of streptocyanine dyes ${ }^{5}$ showed that the bond angles in the polymethine chain deviate from $120^{\circ}$, they are $2.5^{\circ}$ less at atoms of higher electron density, but $4.5^{\circ}$ higher at atoms of lower density.

It can be assumed that the geometry observed for the stable ground state changes correspondingly to the alteration of the electron density in the excited state. The role of this fact in the isomerization process is not known.

The isomerization of polymethine dyes is assumed to proceed by rotation around a bond within the polymethine chain. Quantum chemical calculations of the energy and charge distributions as a function of the twisting angle in the ground and first excited state were done by Dietz et al. ${ }^{6}$ In both states maxima of the potential energy were found at a twisting angle of $90^{\circ}$, but under consideration of the solvent polarization (solvation model) the barriers became shallow and even a flat valley occurred at $90^{\circ}$. In symmetrical polymethine dyes the charge density is minimal at the central atom in the excited state. A rotation around a bond at the central atom seems to be the most probable way of isomerization ${ }^{7}$.

The model of the isomerization follows the quantum chemical calculations done by Orlandi and Siebrand ${ }^{23}$ for stilbene, in which the isomerization proceeds into a twisted state. This model has also been discussed by Rulliere ${ }^{24}$ for polymethine dyes. The quantum chemical calculation under consideration of the solvent polarity ${ }^{6}$ seems to justify this assumption.

Laser spectroscopic methods of high time resolution especially the excite and probe technique allows to study not only the excited state relaxation, but also the photoisomerization kinetics. The formation of photoisomers have been observed by the increase of the corresponding absorption spectra (e.g. ${ }^{8,9}$ ). The solvent influence on relaxation and isomerization is strong in polymethine dyes (e.g. ${ }^{18,20,25}$ ) and can be characterized by the macroscopic viscosity ${ }^{11-13}$.

Often specific interactions between solvent and solute play an important role ${ }^{17}$. In comparison to the gas phase the solvent mostly accelerates the kinetics of relaxation and isomerization (e.g. ${ }^{10}$ ).

In this work we studied the processes of the excited state relaxation 
and photoisomerization as well as the thermal back reaction in the dyes: BMC and DODCI. Both dyes have the same polymethine chromophor, but different terminal groups. The chromophor is a heptamethine cyanine group. BMC shows $\left(\mathrm{CH}_{3}\right)_{2}$-terminal groups linked to the nitrogen atoms, whereas DODCI exhibits bulky terminal double rings with oxygen as a heteroatom (see formula).

BMC: bis-dimethylamino heptamethine perchlorate<smiles>CCCCCCC(=O)OC(C)(C)C(=O)[O-]</smiles>

DODCI: 3.3'-diethyl oxidicarbocyanine iodide<smiles>CCN1CC(C=CC=CC2Cc3ccccc3O2)CC1=O</smiles>

We hoped to get a better insight into the kinetic processes from the comparison of the experimental results obtained in both dyes. Picosecond spectroscopic studies of BMC at various solvents and at a series of temperatures have been performed in an earlier paper ${ }^{14}$. Now the quantum yield of the photoisomeriztion was determined with an equipment which allowed a higher accuracy of measurement than in the past. The back-reaction of the photoisomer of BMC has never been measured before, but only estimated in an earlier paper ${ }^{15}$.

DODCI is one of the often used saturable absorbers in mode locked dye lasers. This dye was subject of numerous time-resolved spectroscopic studies ${ }^{16-20}$. Dempster et al. ${ }^{16}$ found a photoisomer in flash photolysis studies, Velsko et al. studied the dependence of the fluorescence lifetime of DODCI on solvent properties ${ }^{18-20}$. Our investigation of DODCI concerns the photoisomerization, i.e. the formation process, the photoisomer absorption spectrum and the quantum yield of the isomerization.

\section{EXPERIMENTAL RESULTS}

The experiments were performed with an excite- and probespectrometer described elsewhere ${ }^{22}$. For excitation the second har- 
monic of the Nd:phosphate glass laser at $527 \mathrm{~nm}$ was used with a pulse duration of $5 \mathrm{ps}$ and an energy of about $1 \mathrm{~mJ}$.

In Figure 1 the $\triangle \mathrm{D}$-spectrum of $\mathrm{BMC}$ solved in ethanol is shown at the maximum of excitation ( $0 \mathrm{ps})$ and 500 ps later. The spectrum at $0 \mathrm{ps}$ consists in the bleaching at short wavelengths and the stimulated fluorescence at longer wavelengths. The kinetics was studied in an earlier paper ${ }^{14}$ using the bleaching, the excited state absorption at $430 \mathrm{~nm}$ and the fluorescence. The excited state lifetime in ethanol amounts to $\tau=(36 \pm 5) \mathrm{ps}$. The $\Delta \mathrm{D}$-values in the bleaching region at 0 ps is proportional to the number of the excited molecules, whereas the corresponding values at a delay of $500 \mathrm{ps}$ are a measure for the amount of the photoisomer formed. Moreover the absorption spectrum of the photoisomer is seen. From the relation of $\Delta D$-values within the bleaching, $\Delta \mathrm{D}(500 \mathrm{ps}) / \Delta \mathrm{D}$ (ops) the isomerization quantum yield can be estimated. In this experiment with 5 ps pulses at $527 \mathrm{~nm}$ for excitation an photoisomerization quantum yield of $\phi_{\text {iso }}=0.7 \pm 0.1$ was determined in ethanolic solution of BMC. Former$1 \mathrm{y}^{14}$ we worked with pulses of $25 \mathrm{ps}$ duration at $532 \mathrm{~nm}$. It could not be excluded that part of the photoproduct emerging within the 25 ps laser pulse was also excited. Hence, the photoisomer concentration was lower than in the present experiment with the shorter pulses and negligible photo-back-reaction.

The photoisomerization quantum yield of DODCI in ethanol amounts to $0.08^{16}$, in methanol we found $\phi_{\text {iso }}=0.15$ and in ethylene glycol $\phi_{\text {iso }}=0.04$.

The $\Delta \mathrm{D}$-spectrum and the kinetics of the photoisomerization is

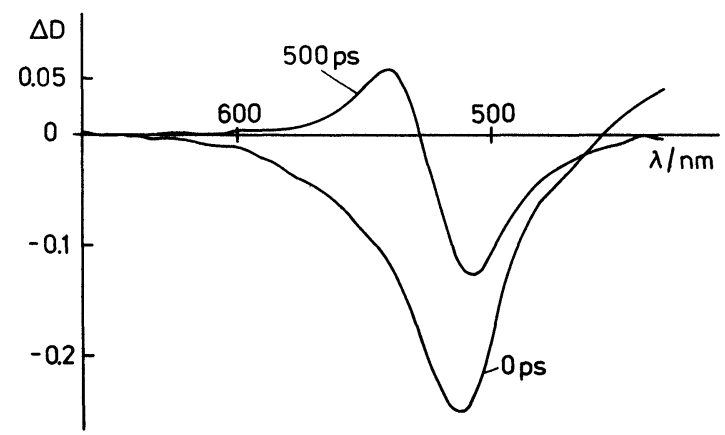

Figure $1 \Delta \mathrm{D}$-spectrum of BMC $\left(10^{-4} \mathrm{~mol} / \mathrm{l}\right)$ in ethanol at $0 \mathrm{ps}$ and $500 \mathrm{ps}$ after excitation by light pulses of 5 ps at $\lambda=527 \mathrm{~nm}$. 
demonstrated in Figure 2. Figures $2 \mathrm{a}$ shows the $\Delta \mathrm{D}$-spectrum of DODCI at $0 \mathrm{ps}$ in a wide spectral range taken by the spectrometer described $\mathrm{in}^{27}$. An excited state absorption with a maximum at $(442 \pm 5) \mathrm{nm}$ and an absorption coefficient of 0.3 with respect to that of the bleaching $S_{0}-S_{1}$ band was observed. A normalized stationary
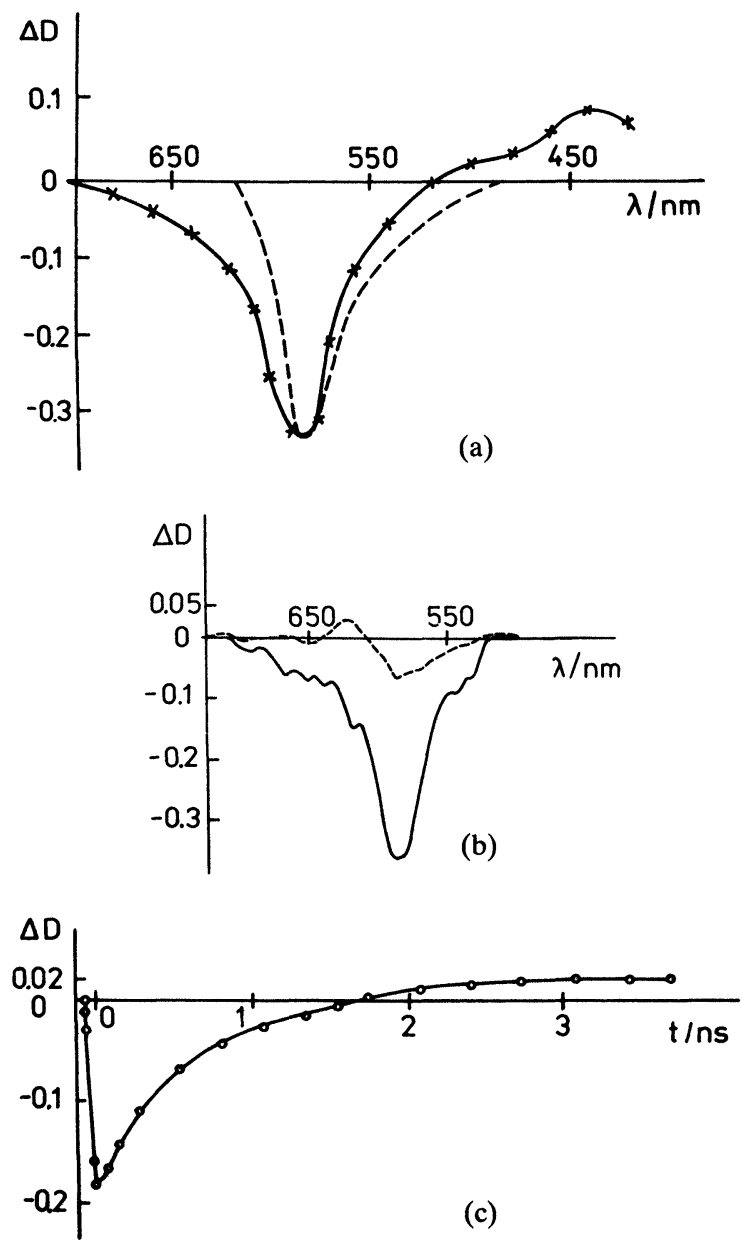

Figure $2 \Delta \mathrm{D}$-spectra of DODCI in methanol. (a) at $0 \mathrm{ps}(-)$ measured by the spectrometer described in ${ }^{27}$ and a normalized stationary spectrum (----). (b) at $0 \mathrm{ps}$ $(-)$ and at $5 \mathrm{~ns}$ delay $(----)$ measured by the spectrometer described in ${ }^{22}$. (c) kinetic $\Delta \mathrm{D}$-curve at the probe wavelength of $615 \mathrm{~nm}$ with the spectrometer described $\mathrm{in}^{28}$. 
absorption spectrum (taken by the spectrometer "Specord" UV/VIS) is depicted for comparison. It shows that the excited state absorption continues in the spectral range of the $S_{0}-S_{1}$ band bleaching. The $\Delta \mathrm{D}$-spectrum at $5 \mathrm{~ns}$ delay and the kinetic curve in the Figure $2 \mathrm{~b}$ and $2 c$, respectively, show the photoisomer spectrum of DODCI and the formation of one. At the probe wavelength $615 \mathrm{~nm}$ the kinetic curve shows an initial negative $\Delta \mathrm{D}$-value caused by the amplified fluorescence, but after about $2 \mathrm{~ns}$ the absorption of the photoisomer preponderates.

An analysis showed that the function $\Delta \mathrm{D}(t)$ contains only one exponential, i.e. the formation law of the photoisomer and the depletion of the fluorescent $S_{1}$ state follows the same exponential time function. The thermal back-reaction of the photoisomer to the stable one was studied in a classical flash experiment. Both dyes have photoisomer lifetimes of a few milliseconds at room temperature. As an example the spectra and the kinetics of the back-reaction of BMC are presented in Figure 3. The spectral parameters of the dyes in the ground and in the excited state will be discussed in the next section.

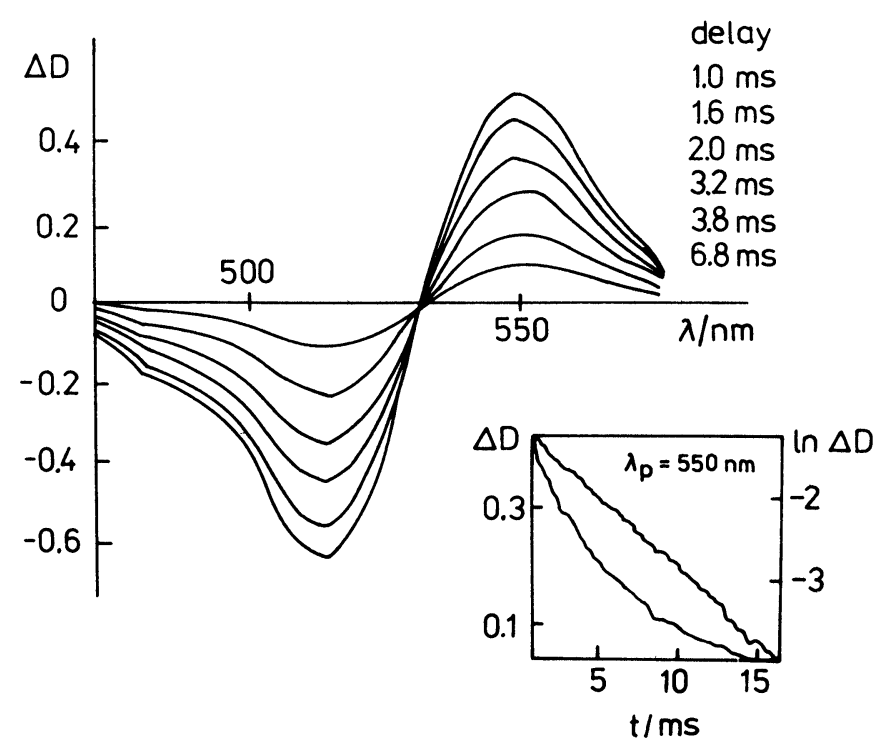

Figure $3 \Delta \mathrm{D}$-spectra of BMC in ethanol after excitation by a flash, insert: kinetics of the thermal back-reaction taken at the probe wavelength of $550 \mathrm{~nm}$. 


\section{DISCUSSION}

For a comparison of the properties of the dyes the spectral and photophysical parameters measured in this paper and reported in other papers are represented in the Tables I and II.

The radiative lifetime of both dyes is almost equal, i.e. the chromophor, but not the terminal groups effect this parameter. We found further characteristics which are similar in both dyes. The excited state absorption coefficient amounts to about 0.3 of that of the $S_{0}-S_{1}$ absorption band and the energy difference between the participating levels $S_{1}$ and $S_{n}$ is 1.4 times that of the $S_{0}-S_{1}$ distance for both dyes. The wavenumber distance between the absorption maxima of the two isomers is equal for $\mathrm{BMC}$ and DODCI within the experimental error. The back-reaction rate at a given temperature and solvent, the Arrhenius factor and the activation energy differ only slightly for the dyes, i.e. the kinetic behaviour of both photoisomers in their ground states is quite similar.

From these results we conclude that the dyes form photoisomers of the same kind, probably by rotation of molecular parts around the same bond. For DODCI the rotation around the bond at the central atom is favored from steric reasons, as confirmed by quantum chemical

Table I Spectral parameters of the stable isomer and the photoisomer of BMC and DODCI solved in ethanol.

\begin{tabular}{lllll}
\hline & \multicolumn{2}{c}{ BMC } & \multicolumn{2}{c}{ DODCI } \\
& Stable isomer Photoisomer & Stable isomer & Photoisomer \\
\hline $\begin{array}{l}\text { Fluorescence } \\
\lambda(\mathrm{nm})\end{array}$ & 542 & $590 \pm 10$ & $625 \pm 10$ & $660 \pm 5$ \\
$\begin{array}{c}\text { Absorption } \\
\lambda_{\mathrm{A}}(\mathrm{nm})\end{array}$ & 512 & $545 \pm 5$ & 582 & $620 \pm 1$ \\
$\varepsilon_{\mathrm{A}}\left(\frac{1}{\mathrm{~mol}} \mathrm{~cm}\right)$ & $1.56 \cdot 10^{5}$ & $(0.55 \pm 0.1) \cdot 10^{5} \mid 2.38 \cdot 10^{5}$ & $(1.55 \pm 0.3) \cdot 10^{5}$ \\
$\begin{array}{l}v_{\mathrm{s}}-v \mathrm{PI}\left(\mathrm{cm}^{-1}\right) \\
\text { Excited state } \\
\quad \begin{array}{l}\text { absorption } \\
\lambda_{\mathrm{A}}(\mathrm{nm})\end{array}\end{array}$ & 400 & $1190 \pm 100$ & & $1180 \pm 100$ \\
$\frac{\varepsilon\left(\mathrm{S}_{1}-\mathrm{S}_{\mathrm{n}}\right)}{\varepsilon\left(\mathrm{S}_{0}-\mathrm{S}_{1}\right)}$ & $0.3 \pm 0.1$ & & & \\
$\frac{\Delta \mathrm{E}\left(\mathrm{S}_{1}-\mathrm{S}_{\mathrm{n}}\right)}{\Delta \mathrm{E}\left(\mathrm{S}_{0}-\mathrm{S}_{1}\right)}$ & $1.37 \pm 0.1$ & & $0.28 \pm 0.03$ & \\
\hline
\end{tabular}


Table II Photophysical parameter of BMC and DODCI in ethanol.

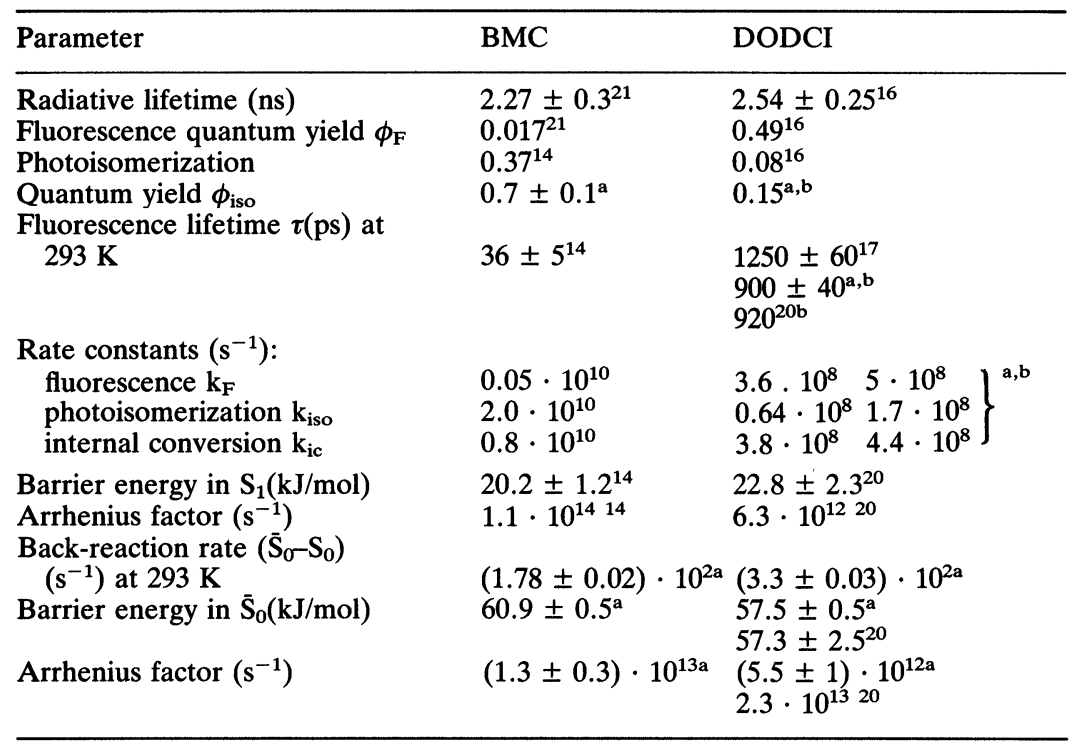

${ }^{a}$ This work. ${ }^{\mathrm{b}}$ in $\mathrm{MeOH}$.

calculations $^{7}$. In BMC several isomers are imaginable, but experimentally only one photoisomer could be detected by the excite-and-probe technique.

The structure of the photoisomers cannot be determined by this technique. Detailed information on the geometry can be obtained from time resolved Raman scattering, especially CARS methods (see e.g. $\left.{ }^{26}\right)$.

Whereas the parameters concerning the photoisomer in its ground state are very similar in both dyes, the kinetic parameters of the excited state are quite different.

The $\mathrm{S}_{1}$-lifetime and the photoisomerization yield are essentially greater in BMC than in DODCI. The rate parameters in Table II were calculated from the experimental data under the assumption that the simple relation holds:

$$
\phi_{\text {iso }}=\mathrm{k}_{\text {iso }} \tau
$$

( $\tau$ is the $S_{1}$-lifetime). The dominant rate parameter in BMC relaxation is that of the photoisomerization, it is two orders of magnitude higher 
than in DODCI. The reason for this is not the activation energy, which is also nearly equal in both dyes, but the frequency factor.

To describe this result the transition state theory ${ }^{29}$ of Eyring seems to be suitable. It predicts for the overall rate constant

$$
k=\frac{k_{B} T}{h} \exp (\Delta S / R) \cdot \exp (-H / R T)
$$

( $\mathrm{k}_{\mathrm{B}}$-Boltzmann constant, $\mathrm{h}$-Planck's constant, $\mathrm{R}$ - gas constant, $\mathrm{H}=\mathrm{E}-\mathrm{Barrier}$ enthalpy). Thereby the frequency factor is

$$
A=\frac{h_{B} T}{h} \exp (\Delta S / R)
$$

In BMC the high frequency factor means an increase of the entropy going from the primary excited state to the transition state $(\Delta \mathrm{S}=+14.9 \mathrm{~J} / \mathrm{K})$. In DODCI the entropy decreases $(\Delta \mathrm{S}=-8 \mathrm{~J} / \mathrm{K})$. That gives a hint to the higher number of realizations of a transition state in BMC than in DODCI. The picture of several realization possibilities of the transition state in $\mathrm{BMC}$ is understandable, because of the flexibility of the polymethine chain and the quasi free rotation of the small terminal $\left(\mathrm{CH}_{3}\right)_{2}$-groups. This fact also implies an effective isomerization and relaxation.

DODCI has a more rigidized structure because the oxygen atoms block the motion of the external $\mathrm{C}-\mathrm{C}$-bonds. Moreover the bulky terminal groups allow torsional vibrations of lower frequencies than in BMC. These structural features of DODCI render the isomerization and the radiationless relaxation more difficult, whereas the radiative relaxation becomes more efficient.

\section{References}

1. F. Dörr, J. Kotschy and H. Hausen, Ber. Bunsenges, 69, 11-16 (1965).

2. F. Baumgärtner, E. Günther, G. Scheibe, Z. f. Elektrochemie, 60, 570 (1956).

3. J. Fabian and H. Hartmann, Light Absorption of Organic Colorants. Springer V. Berlin, Heidelberg, New York (1980).

4. V. A. Kuzmin and A. P. Darmanyan, Chem. Phys. Lett. 54, 159 (1978).

5. R. Radeglia, J. Mol. Struct. 17, 47-52 (1973).

6. F. Dietz, W. Förster, C. Weiss, A. Tadger and N. Tyutyulkov, J. Signal, AM 9, 177-190 (1981).

7. T. Tani, Photogr. Sci. Eng. 16, 258 (1972).

8. S. Rentsch, R. Danielius and R. Gadonas, Chem. Phys. 59, 9 (1981).

9. S. Rentsch, R. Danielius and R. Gadonas, Chem. Phys. Lett. 84, 446 (1981). 
10. B. I. Greene, R. M. Hochstrasser, Chem. Phys. 48, 289 (1980).

11. J. S. McCascill and R. G. Gilbert, Chem. Phys. 44, 398 (1979).

12. B. Wilhelmi, Chem. Phys. 66, 351 (1982).

13. M. Kaschke, J. Kleinschmidt and B. Wilhelmi, Laser Chemistry, 5 (1985).

14. S. Rentsch, R. Gadonas and A. Piskarskas, Chem. Phys. Lett. 104, 235 (1984).

15. F. Dietz, S. Rentsch, Chem. Phys. 86, 145 (1985).

16. D. N. Dempster, T. Morrow, R. Rankin and G. F. Thompson, J. Chem. Soc. Farady Trans. 2, 68, 1479 (1972).

17. J. Jaraudias, J. Photochemistry, 13, 35 (1980).

18. S. P. Velsko and G. R. Fleming, Chem. Phys. 65, 59-70 (1982).

19. G. R. Fleming, A. E. W. Knight, I. M. Morris, J. M. Robins and G. W. Robinson, Chem. Phys. Lett. 49, 1 (1977).

20. S. P. Velsko, D. H. Waldeck and G. R. Fleming, J. Chem. Phys. 78, 249 (1983).

21. S. Belke, Dissertation Jena (1981).

22. T. Damm, M. Kaschke, M. Kresser, F. Noack, S. Rentsch and W. Triebel, Exp. Techn. Phys. 33, 409-416 (1985).

23. G. Orlandi and W. Siebrand, Chem. Phys. Lett. 30, 353 (1975).

24. C. Rulliere, Chem. Phys. Lett. 43, 303 (1976).

25. V. Sundström and T. Gillbro, Chem. Phys. 61, 257 (1981).

26. W. Werncke, Tschoe Jong Tschol, H. J. Weigmann, M. Pfeiffer, A. Lau, S. Rentsch, A. Graneß, J. Raman Spectr. (in press).

27. R. Gadonas, R. Danielius and A. Piskarskas, Kvant. Elektr. 8, 667 (1981).

28. H. Bergner, V. Brückner, R. Gase, A. Schlisio and B. Schröder, Exp. Techn. Physik. 30, 407 (1982).

29. E.g. in Einführung in die Reaktionstheorie. Ed. by E. Heublein, VEB Deutscher Verlag für Grundstoffindustrie, Leipzig (1984). 